\title{
Allocation of Decision-making Authority *
}

\author{
MILTON HARRIS ${ }^{1}$ and ARTUR RAVIV ${ }^{2}$ \\ ${ }^{1}$ Graduate School of Business, University of Chicago; ${ }^{2}$ Kellogg School of Management, \\ Northwestern University
}

\begin{abstract}
This paper addresses the question of what determines where in a firm's hierarchy investment decisions are made. We present a simple model of a CEO and a division manager to analyze when the CEO will choose to allocate decision-making authority over an investment decision to a division manager. Both the CEO and the division manager have private information regarding the profit maximizing investment level. Because the division manager is assumed to have a preference for "empire", neither manager will communicate her information fully to the other. We show that the probability of delegation increases with the importance of the division manager's information and decreases with the importance of the CEO's information. A somewhat counterintuitive result is that, in some circumstances, increases in agency problems result in increased willingness of the CEO to delegate the decision. We also characterize situations in which the CEO prefers to commit to an allocation of authority ex ante, instead of deciding based on her private information. Finally, even though the division manager is biased toward larger investments, we show that under certain conditions, the average investment will be smaller when the decision is delegated. These results help explain some findings in the empirical literature. A number of other empirical implications are developed.
\end{abstract}

\section{Introduction}

This paper addresses the question of what determines where in a firm's hierarchy investment decisions are made. The fact that many firms have detailed rules for determining the allocation of decision-making authority suggests that the allocation is not a matter of indifference but instead has important efficiency implications. Empirically, Taggart (1987) reports that some projects are approved at the division level, while others require higher-level review. Which projects require higher approval may be correlated with size (e.g., those likely to require more than a given expenditure are approved at higher levels) or determined by the nature of the project (e.g., new product lines must be approved at higher levels). Ross (1986) finds that

$\star$ We thank Sudipto Dasgupta, Wouter Dessein, Jeff Ely, Mike Fishman, Ehud Kalai, John Matsusaka, Canice Prendergast, Chester Spatt, Lars Stole, Jan Zabojnik, two anonymous referees, participants at the 2002 Utah Winter Finance Conference, the 2002 European Finance Association Annual Meetings, the Harvard/MIT Organizational Economics Workshop, the 2002 University of Illinois Bear Markets Conference, and workshops at the University of Chicago and USC for helpful comments. Financial support from the Center for Research in Security Prices at the University of Chicago Graduate School of Business is gratefully acknowledged. 
the level at which decisions are made increases with investment size. Relatively little theoretical work has been done on these issues in the economics literature.

We develop a theory of the allocation of decision-making authority based on private information and differences in preferences. In particular, we argue that, in most firms, information is distributed across various levels of management. Ideally, investment decisions should be based on all the information available to the management collectively. Agency problems, however, prevent full communication. Moreover, in our view, the extent of communication is determined in part by the allocation of decision-making authority. Consequently, this allocation is determined by how information is distributed, how the allocation affects the incentives of managers to communicate their information, and the nature of the decision that would be taken by each manager if given the authority.

Although there is a large agency literature in finance concerned with incentive problems that arise from delegation, this literature takes delegation of decisions as given. The focus of this literature is to explain how compensation contracts, capital structure, capital budgeting schemes, or combinations of these arise as solutions to the incentive problem. ${ }^{1}$ Recently Harris and Raviv (1998) consider the issue of when one would expect investment decisions to be delegated, using a "mechanism design" framework. In that framework, in equilibrium, all information is truthfully reported to the CEO, and the optimal capital budgeting scheme specifies a decision as a function of this report. Thus, strictly speaking, the model determines only the capital allocation, not who makes the allocation decision. Results regarding delegation of the capital budgeting decision are obtained by observing that the equilibrium of the optimal scheme can be implemented by a game in which, in some cases, the capital allocation is left to the division manager. Of course, this is only one possible interpretation. An equally valid interpretation is that the CEO makes the decision based on the report of the division manager. Our goal in this paper is to endogenize the allocation of decision-making authority using a model in which this allocation truly matters.

We adopt a simple model of delegation based on the framework of Crawford and Sobel (1982). In particular, our model consists of two managers, the CEO and a division manager. Both the $\mathrm{CEO}$ and the division manager have private information about the optimal size of an investment. We assume that the CEO has the authority to choose who makes the investment decision, herself or the division manager. Thus we assume that the CEO can commit to transfer decision-making authority to the division manager. ${ }^{2}$ Both managers have private information regarding the profitability of the investment decision. The CEO cares only about profits and will therefore choose the investment that maximizes profits, given whatever information she has at the time. That is, the CEO perfectly represents the preferences of the

\footnotetext{
1 See, e.g., Berkovitch and Israel (2004), Harris and Raviv (1996) and Bernardo, et al. (2001).

2 Such a commitment could take the form of an enforceable contract as in Maskin and Tirole (1999) or, in the spirit of Grossman and Hart (1986) and Hart and Moore (1990), by transferring control of an asset.
} 
shareholders. The division manager, on the other hand, cares about both profits and investment size directly. He will choose an investment that is larger than the profitmaximizing investment, given whatever information he has at the time. We assume that the parties cannot commit to a decision rule (as a function of any messages from the two parties) that is not ex post optimal for the decision-maker. This implies, in particular, that the parties cannot commit to an incentive-compatible decision rule that renders full disclosure a Nash equilibrium as in a Revelation Principle setting. ${ }^{3}$ For most of the paper, we consider two specific regimes. In the centralization regime, the division manager reports a value of his private information to the CEO who then chooses the investment size. In the delegation regime, the CEO reports a value of her private information to the division manager who then chooses the investment size. ${ }^{4}$ Our results show which of these two regimes is optimal. In either regime, strategic behavior on the part of the party who does not make the decision prevents full communication of his or her private information to the decision-maker. Centralization avoids the division manager's bias but will result in under-utilization of the division manager's information. Delegation results in under-utilization of the CEO's information and in larger-than-optimal investment due to the manager's bias. The extent to which strategic behavior prevents communication differs between the two allocations of authority, and the size of this difference depends on the nature of the information and the extent of the division manager's bias. ${ }^{5}$ Which allocation is optimal, therefore, depends on these factors.

The results are derived for two alternative environments. In the first environment, the CEO allocates decision-making authority before observing her private information. We refer to this as the ex ante environment. In the second environment, which we call the ex post environment, the assignment is made after the CEO observes her private information. We also compare the two environments from the point of view of the shareholders.

In the ex ante environment, the assignment of decision-making authority is based only on commonly known characteristics of the investment, e.g., whether the investment is in producing a new product or increasing output of an old product. We refer to these characteristics as project type. We show that for the CEO to delegate the decision to the division manager, the division manager's information must be strictly more important (in a way that will be made precise below) than the CEO's. The intuition for this result is simple. The advantage of delegation is that it utilizes the division manager's information more fully. The disadvantages are that the division manager's decision is biased relative to first-best and that some of the CEO's information is lost. If the division manager's information is sufficiently more important, the net gain in information utilization outweighs the loss due to

\footnotetext{
3 This will be explained in Section 2. One can show by example (available on request) that commitment to a decision rule that is not ex post optimal for the decision-maker allows the decision maker to be strictly better off.

4 The extent to which this focus is without loss of generality is discussed in Section 6.

5 This last point is somewhat subtle and has been missed by other authors (see below).
} 
the division manager's bias. Moreover, an increase in the importance of the division manager's (CEO's) information, to the extent that it affects the assignment of decision-making, shifts the assignment from the CEO (division manager) to the division manager (CEO) but never the reverse. We also show that, for some types of project, an increase in the division manager's bias can shift the decision from the CEO to the division manager. This result is counter to the simple intuition that when agency problems increase, the CEO should be less willing to delegate. ${ }^{6}$ The problem with this intuition is that it ignores the differential effect of an increase in the division manager's bias on the amount of communication that occurs under the two regimes. In particular, the increase in agency problems can reduce the amount of communication that occurs under centralization, relative to delegation. This effect can outweigh the direct effect of the increase in agency problems.

In the ex post environment, the CEO observes her private information before allocating decision-making authority, i.e., the assignment is based on the specifics of the project as well as on project type. Here we show that the CEO will delegate the investment decision when her private information indicates that the ideal decision is more likely to be close to the division manager's preferred choice. We also show that delegation becomes more likely when the division manager's informational advantage increases or the CEO's decreases.

The above discussion assumes that the environment is exogenous, i.e., either that the CEO is forced to commit to an allocation of authority ex ante or cannot so commit. What if the CEO could choose to commit (either to delegation or to centralization) prior to observing her private information, or wait to observe her private information before choosing a regime? We show that the CEO never benefits from committing to centralize. In contrast, when the CEO's information is not very important, she is strictly better off committing to delegate ex ante rather than waiting to decide after observing her private information. In such cases, the delegation decision itself, if based on the CEO's private information, reveals too much relative to the benefits of conditioning the delegation decision on that information. ${ }^{7}$ On the other hand, if the CEO's information is sufficiently important, she strictly prefers to observe her private information before deciding whether to delegate or not.

To interpret these results empirically, consider two types of projects. Suppose the CEO's information is more important for the first project type than for the second project type, and the division manager's information is more important for the second type of project than for the first type. For example, it is reasonable to suppose that the CEO's information is likely to be more important for new plant projects than for plant expansion, because the former are likely to involve more interactions with other parts of the company. The division manager's information

\footnotetext{
6 For example, Jensen and Meckling (1992, p. 117) claim that increasing agency costs tends to reduce delegation, and Dessein (2002), to be discussed presently, derives this result in a model similar to ours.

7 We are grateful to an anonymous referee for suggesting this possibility.
} 
is likely to be more important for plant expansion than for new-plant projects, because of his familiarity with the existing plant(s). Other examples might include new product introduction vs. expansion of existing products, or entering a new geographical market vs. expansion in one's current territory. Our results for both environments imply that the first type of project is more likely to be centralized than the second type, e.g., new plant, new product, and new market decisions are more likely to be centralized than plant expansion or product expansion decisions. This is consistent with Taggart's (1987) observation that new product lines are approved at higher levels.

It also seems reasonable to assume that projects of the first type tend to be larger than those of the second type. For example, investments in plant expansions tend to be smaller on average than investments in new plants, introducing new products tends to require larger investments than expanding existing products, etc. Under this assumption, for both environments, centralized decisions may, on average, be characterized by larger investments than delegated decisions, even if the division manager is biased toward larger investments. This result is consistent with the observations of Taggart (1987) and Ross (1986).

Our model is most closely related to that of Crawford and Sobel (1982), as mentioned above, and Dessein (2002). Crawford and Sobel focus on the amount of information that will be communicated by an informed manager, assuming that the CEO makes the decision. That is, Crawford and Sobel, by analyzing the extent of communication, provide the framework for considering delegation but do not consider it themselves. Dessein uses the Crawford-Sobel framework to consider whether it is optimal to delegate the decision to the division manager. He shows that, for the version of his model that is most similar to ours, centralization is optimal only when the division manager's information is less important than his bias toward larger projects. In this case, the agency problem is so severe that the division manager refuses to communicate any information. That is, either the CEO delegates to the division manager or the CEO decides without any participation by the division manager. ${ }^{8}$ Thus, in a sense, Dessein's model is not so much about delegation as it is about whether to have an agent at all. We provide a rationale for centralization in which the division manager actually plays a role by communicating some of his private information to the CEO. This allows us to derive results regarding the determinants of the regime choice and compare the size of investments made under each regime. These results are driven by our assumption

8 The complete lack of communication by the division manager under centralization in Dessein's model holds only for the version of his model that is similar to ours and allows closed-form solutions. Dessein shows, however, using simulations with a broader class of specifications, that "delegation is optimal unless the bias is so large that communication is almost uninformative" (p. 813). In particular, when centralization is optimal, the division manager's message will be identical for more than $98 \%$ of the realizations of his information. Marino and Matsusaka (2005) analyze a model that is essentially the same as in Dessein (2002), except that in their model, the agent can be of only two types. They show that, for some parameter values, centralization results in first-best and is therefore better than delegation. 
that both the CEO and the division manager have private information relevant for the decision. This is in contrast to the Crawford-Sobel and Dessein models in which only the division manager has relevant private information. Another point of departure with Dessein is that we consider an environment in which the CEO's delegation decision is allowed to depend on her private information.

Prendergast (2002) also considers the issue of when a decision will be delegated to a biased agent, although this is not the main focus of his analysis. He obtains a result similar to that of Dessein (2002), namely that centralization is optimal only when the division manager's private information is below a cutoff (as in Dessein, only the subordinate has relevant private information).

Another related paper is Aghion and Tirole (1997) which is primarily concerned with the allocation of "real" and "formal" authority. "Formal" authority is the authority to make the decision, while "real" authority refers to the party who effectively makes the decision. The distinction between formal and real authority in Aghion and Tirole is driven by their assumptions that the information of one party is a perfect substitute for that of the other and that information is costly, so agents need incentives to produce it. In our model, by contrast, the two parties have complementary information, and it is free. Consequently, in our model, there is no distinction between formal and real authority: whoever has authority to make the decision actually makes it based on his or her own information and input from the other party. Moreover, in Aghion and Tirole, the extent of communication does not depend on the allocation of formal authority or on any of the exogenous parameters of the model as it does in the current paper. ${ }^{9}$

The remainder of the paper is organized as follows. The next section lays out our model and describes the two decision regimes, delegation and centralization. In Section 3, we derive the equilibria of the two regimes, and in Section 4, we determine the conditions under which the CEO chooses each regime. Section 5 contains the empirical results. We consider regimes other than centralization and delegation in Section 6, and Section 7 concludes.

\section{Model}

We focus on expertise as the driving force that determines the assignment of the decision. Thus, we must include in the model an impediment to communication, for if either manager will communicate fully his expertise to the other, then the assignment of the decision is irrelevant. In particular, we must construct a model in which the Revelation Principle does not apply. If the Revelation Principle applies, then it is optimal to specify a decision rule that provides incentives for the two managers to communicate their information fully and truthfully, given that the decision specified by the rule will be implemented. In this case, the allocation of decision-

\footnotetext{
9 On the topic of real vs. formal authority, see also Baker, et al. (1999). Another related paper is Bhattacharyya and Singh (1999) which considers the allocation of the right to decide the method of sale of corporate assets.
} 
making authority is, at best, a matter of interpretation. To avoid this, we assume that managers cannot commit to such a decision rule and that the communication problem cannot be solved by the managers' compensation contracts. Recall, however, that we assume the CEO can commit to delegating decision-making authority to the division manager.

\subsection{INFORMATION, TECHNOLOGY, AND PREFERENCES}

The model consists of a CEO and a division manager who must make an investment decision, denoted by $y$. The first-best investment decision is determined by an unobserved factor, $s$, about which each manager has private information. In particular, the CEO and division manager privately observe signals, $p$ and $a$, respectively, and the first-best decision is determined by the sum of these two signals, i.e., $s=p+a$. The distribution of $\tilde{a}$ is assumed to be uniform on $[0, A]$. The distribution of $\tilde{p}$ is assumed to be uniform on $[0, P]$. For most of our results, only the lengths, not the locations, of the supports of $a$ and $p$ play any role. Thus, for the most part, the assumption that both intervals start at zero is without loss of generality. When this assumption does affect the results, we will relax it. ${ }^{10}$

Two interpretations of the parameters $A$ and $P$ are possible. First, since the division manager knows $a$ while the CEO knows only that $a$ is in the interval $[0, A]$, the larger is $A$ the greater is the division manager's informational advantage over the CEO with respect to $\tilde{a}$. Similarly, $P$ can be interpreted as the CEO's informational advantage over the division manager with respect to $\tilde{p}$. An alternative interpretation of $A$ and $P$ is available if we allow the factor $s$ to be a linear combination of $a$ and $p$, e.g., $s=\alpha a+\pi p$ (with $\alpha$ and $\pi$ positive). In this case, $\alpha$ and $\pi$ can be interpreted as the importance of $a$ and $p$, respectively, in choosing $y$. But, in that case, we may simply redefine the variables $\tilde{a}$ and $\tilde{p}$ to be new variables uniformly distributed on $[0, \alpha A]$ and $[0, \pi P]$, respectively. All results will go through as before with the parameters $A$ and $P$ replaced by $\alpha A$ and $\pi P$, respectively. Thus, we see that increasing the importance of a player's private information is equivalent to increasing that player's informational advantage. We will refer to both interpretations in what follows.

Formally, the pair must choose the investment level, $y$. Firm profit is assumed to decrease with the distance between the investment level, $y$, and the first-best level, $s$. In particular, we assume profit equals a constant minus $(y-s)^{2}$. The constant may be interpreted as the first-best level of profit. The CEO's objective in choosing investment is simply to maximize expected profit. This is equivalent to minimizing the expected loss, $E(y-\tilde{s})^{2}$.

The division manager is assumed to care about both profits and investment size. In particular, the division manager prefers larger investments, other things equal, i.e., he has a preference for "empire". The extent of this agency problem between

10 Although some of our results hold for more general distributions, we require uniformity for the comparative statics results. 
the division manager and the CEO preference is measured by a parameter $b>0$. In particular, we assume that the division manager's ideal investment choice, given the first-best level, $s$, is $s+b$, and the cost to him of deviating from this level is quadratic in the distance between $y$ and $s+b$, i.e., is given by $(y-s-b)^{2}$. One can view the preferences of the division manager as being a reduced form that reflects the extent to which the agency problem can be mitigated through compensation schemes. Obviously, we assume such schemes cannot completely eliminate the agency problem. ${ }^{11}$

\subsection{DECISION-MAKING AUTHORITY}

The CEO is assumed to choose who has the authority to make the decision. She can choose one of two regimes: centralization or delegation. ${ }^{12}$ The object of the analysis is to determine the CEO's choice of regime.

If centralization is chosen, the division manager is asked to report to the CEO a value for the division manager's information. The CEO then chooses the investment based on what she can infer from the division manager's report and her own information.

If delegation is chosen, the CEO reports a value for her information to the division manager. The division manager then chooses the investment based on what he can infer from the CEO's report and his own information. The situation is entirely symmetric to centralization.

As already discussed, commitment to a decision rule as a function of the report that does not minimize the decision-making manager's loss, given his or her information at the time, is not allowed. Neither can the decision-making manager commit to make any transfers (positive or negative) to the other manager based on the report.

\section{Equilibrium}

In this section we define equilibrium and calculate equilibrium strategies, beliefs and outcomes of each regime. The equilibrium concept used is Perfect Bayesian Equilibrium. We begin with centralization.

Equilibrium of the centralization regime consists of a reporting strategy for the division manager, as a function of his information, the CEO's posterior beliefs about the division manager's information as a function of the division manager's report, and a decision rule for the CEO as a function of his information and the division manager's report. Formally, an equilibrium of the centralization regime is a reporting rule, $q(\cdot \mid a)$, giving a probability distribution over reports $r$ conditional

\footnotetext{
11 We assume uniform distributions and quadratic loss functions for tractability; as far as we know, this is the only case in which closed form solutions can be obtained. The extent to which our results depend on the quadratic loss functions will be indicated as we derive the results.

12 Other regimes are possible; see Section 6.
} 
on the value $a$ of $\tilde{a}$ observed by the division manager, a posterior distribution, $g(\cdot \mid$ $r$ ), for the CEO giving the posterior probability distribution of $\tilde{a}$ conditional on each possible report, $r$, and an investment choice rule, $y^{*}(p, r)$, giving the CEO's choice of investment $y$ for each value $p$ of $\tilde{p}$ observed by the CEO and each of the division manager's possible reports, that satisfy the following conditions: ${ }^{13}$

- The division manager's report minimizes his expected loss, given his information, $a$, and given the CEO's investment choice rule, $y^{*}(p, r)$,

- The CEO's investment choice rule minimizes her expected loss, given her posterior beliefs, $g(\cdot \mid r)$, about $\tilde{a}$ given the division manager's report, and,

- For each report with positive probability, $g(\cdot \mid r)$ satisfies Bayes' rule.

It is straightforward to check that the equilibrium investment choice is the CEO's information plus the average value of the division manager's information, given the manager's report, i.e., that $y^{*}(p, r)$ must satisfy

$$
y^{*}(p, r)=p+\bar{a}(r)
$$

where $\bar{a}(r)$ is the CEO's posterior expectation of $\tilde{a}$, the manager's information, given the manager's report, $r$. This follows from the fact that with a quadratic loss function, the optimal investment is the expected value of the first-best investment, given one's information, in this case, $p$ and $r$.

Thus, the equilibrium investment decision of the CEO is additive in her information. This implies that the division manager can predict perfectly, for each of his reports, what his utility will be, because the unknown private information of the CEO will always be cancelled by the CEO's choice of investment. Consequently, the equilibrium can be computed by solving for a "reduced form" equilibrium in which the division manager's report minimizes the square of the distance between $\bar{a}(r)$ and $a+b$, the CEO chooses investment equal to $\bar{a}(r)$, and the CEO's posterior is the same as in the original equilibrium. The investment of the original equilibrium is then simply the CEO's private information plus the investment from the "reduced-form" equilibrium, i.e., $p+\bar{a}(r)$.

Since, in this "reduced form" equilibrium, the division manager can predict perfectly, for each of his reports, what his utility will be, the reduced-form equilibrium is exactly of the same form as that of Crawford and Sobel (1982). ${ }^{14}$ Thus,

\footnotetext{
13 A formal statement of these conditions is given in the appendix.

14 The mapping from Crawford and Sobel's notation to ours is as follows. Player $S$ corresponds to our division manager, and Player $R$ corresponds to our CEO. The bias parameter in both cases is denoted $b$. Their state $m$ corresponds to our $a$, and their distribution function $f$ is uniform on $[0, A]$ in our case. The report $n$ in Crawford and Sobel corresponds to our report $r$. The distribution function $q$ has the same meaning in both models (although the arguments are different as already noted). Their distribution function $p$ corresponds to our $g$. Their choice function $y(n)$ corresponds to our $\bar{a}(r)$. Finally, their utility function $U^{S}(y, m, b)$ corresponds to $-(y-a-b)^{2}$ and $U^{R}(y, m)$ corresponds to $-(y-a)^{2}$ in our model.
} 
we may use their results to characterize the reduced-form equilibrium of the centralized regime. ${ }^{15}$ In particular, every equilibrium is of the following form. The division manager's report forms a partition of $[0, A]$, i.e., the division manager divides the interval $[0, A]$ into $N$ subintervals and chooses a report at random from the subinterval to which the true value $a$ belongs. The division manager's report, therefore, reveals only a range in which the true $a$ lies, thus introducing noise into his report. "This represents [the division manager's] optimal compromise between including enough information in the [report] to induce [the CEO] to respond to it and holding back enough so that [her] response is as favorable as possible". [Crawford and Sobel (1982, p. 1432)]. Formally, there are numbers $a_{0}, a_{1}, \ldots, a_{N}$ with $0=a_{0}<a_{1}<\cdots<a_{N}=A$ such that, if $a \in\left[a_{i-1}, a_{i}\right]$, then the division manager chooses his report from a uniform distribution on $\left[a_{i-1}, a_{i}\right]$. It follows that the CEO's posterior on $\tilde{a}$, given the division manager's report, is uniform on the interval that contains the report. Consequently, $\bar{a}(r)$ is the midpoint of the interval that contains $r$. It is shown in Crawford and Sobel (1982, p. 1441) that $a_{i}$ is given by ${ }^{16}$

$$
a_{i}(N)=\frac{i A}{N}-2 i(N-i) b, \quad \text { for } i=0, \ldots, N
$$

From (2) it is easy to show that the width of the interval $\left[a_{i-1}, a_{i}\right]$ increases by $4 b$ for each increase in $i$. Recall that, when the division manager reports $r \in$ $\left[a_{i-1}, a_{i}\right]$, the CEO can infer only that the true value of $\tilde{a}$ is somewhere in the interval $\left[a_{i-1}, a_{i}\right]$. Intuitively, therefore, less information is communicated by the division manager the larger is his reported value of $\tilde{a}$. The reason for this is that, since the CEO knows the division manager is biased toward larger values of $y$, the division manager is more believable when he "recommends small $y$ " (i.e., reports small $r$ ) than when he "recommends large $y$ ".

As shown by Crawford and Sobel, there is at least one equilibrium (as described above) of the centralization game for each $N$ from $N=1$ up to a maximum value $N(b, A)$ determined by the bias parameter $b$ and the length of the support of $\tilde{a}$. Crawford and Sobel's results show that both players' expected loss is decreasing with $N$ over the range from one to the largest value of $N$ for which an equilibrium exists. They argue that the Pareto best equilibrium, corresponding to the largest feasible value of $N$, is a focal equilibrium. We will focus on this equilibrium (for both regimes). A formula for $N(b, A)$ is given in the appendix.

To summarize, the equilibrium of the centralization regime is as follows:

- The division manager informs the CEO as to which subinterval (of a partition) contains the true value of his private information;

\footnotetext{
15 For this result, the quadratic loss function is not essential. Any well-behaved loss function that depends on $y, p$, and $a$ only through a function of the form $y-h(a)-k(p)$ will do.

16 In Crawford and Sobel (1982), $A=1$.
} 
- The CEO optimally chooses $y$ equal to the midpoint of this interval plus the value of her private information, $p$.

The situation in the delegation regime is entirely symmetric to centralization. In the delegation game, the division manager's choice of investment $y$ is given by

$$
y_{m}^{*}(a, r)=a+b+\bar{p}(r)
$$

where $\bar{p}(r)$ is the posterior mean of $\tilde{p}$, given the CEO's report $r$. We compute equilibrium as before using the Crawford and Sobel approach. ${ }^{17}$ Thus the CEO's report is determined by a partition $\left\{p_{i}\right\}$ of $[0, P]$ that is computed in an analogous manner to the partition $\left\{a_{i}\right\}$, i.e.,

$$
p_{i}(N)=\frac{i P}{N}+2 i(N-i) b, \quad i=1, \ldots, N .
$$

Similar to the delegation regime, the width of the interval in which the division manager infers that $\tilde{p}$ is located decreases by $4 b$ for each increase in $i$. Intuitively, more information is communicated by the CEO the larger is his reported value of $p$. As before, the reason is that, since the CEO knows the division manager is biased toward larger values of $y$, the $\mathrm{CEO}$ is more believable when he "recommends large $y$ " (i.e., reports large $p$ ) than when he "recommends small $y$ ".

We can compute the maximum size of the equilibrium partition for the delegation game as before. This size is given by $N(b, P)$.

To summarize, the equilibrium of the delegation regime is as follows:

- The CEO informs the division manager as to which subinterval (of a partition) contains the true value of her private information;

- The division manager optimally chooses $y$ equal to the midpoint of this interval plus the value of his private information, $a$, plus his bias, $b$.

\section{Choice Between Centralization and Delegation}

In this section, we consider the CEO's assignment of the investment decision, the right to choose $y$. There are two ways one can view this assignment: as being made for a type of project, e.g., plant expansion, or for each specific project as it arises.

\footnotetext{
17 The mapping from Crawford and Sobel's notation to ours is slightly different than in the case of centralization. Here, Player $S$ corresponds to our CEO, and Player $R$ corresponds to our division manager. The bias parameter $b$ in Crawford and Sobel becomes $-b$. Their state $m$ corresponds to our $p$, and their distribution function $f$ is uniform on $[0, P]$ in our delegation game. The report $n$ in Crawford and Sobel corresponds to our report $r$, as before. The distribution function $q$ has the same meaning in both models (although the arguments are different as already noted). Their distribution function $p$ corresponds to our $g$. Crawford and Sobel's choice function $y(n)$ corresponds to our $\bar{p}(r)$. Finally, their utility function $U^{S}(y, m, b)$ corresponds to $-(y-p-b+b)^{2}=-(y-p)^{2}$ and $U^{R}(y, m)$ corresponds to $-(y-p-b)^{2}$ in our delegation game.
} 
If the assignment is based on project type, then the CEO chooses the regime before observing her private information. If the assignment is project-specific, the CEO chooses the regime after observing $p$. We consider each of these environments in turn, then compare them to determine when the CEO would want to commit to deciding whether to delegate the investment choice before observing her private information.

\subsection{ASSIGNMENT BASED ON PROJECT TYPE (THE ex ante ENVIRONMENT)}

In this subsection, we assume that the CEO must allocate decision-making authority before learning her private information (i.e., ex ante). In the current model, as we show later, the CEO would prefer to make the delegation decision ex ante only in certain situations. The prevalence of such commitments in actual capital budgeting schemes suggests, however, that factors outside our model make having predetermined assignments of decision authority for each type of project more attractive. Perhaps, for example, there is a gain to having managers know in advance whether a given project will be delegated or not. Consequently, we first investigate when the CEO will delegate the investment decision, given that this determination is based only on project type.

In our model, project type is determined by the range of possible values of $\tilde{p}$ and $\tilde{a}$, i.e., by $P$ and $A$, and by $b$. That is, empirically, we view $A$ and $P$ as being characteristic of a fairly narrow set of projects of a given type. For example, all expansions of production capacity of a given product of the firm might be of the same type, i.e., all have the same values of $A$ and $P .{ }^{18}$ We therefore assume that the CEO chooses between the two assignments knowing $P, A$ and $b$ but before observing $\tilde{p}$.

In the centralization regime, using (2), the CEO's ex ante expected loss for the equilibrium of size $N$ is given by

$$
\frac{1}{A} \sum_{i=1}^{N} \int_{a_{i-1}}^{a_{i}}\left(\frac{a_{i-1}+a_{i}}{2}-a\right)^{2} d a=\frac{1}{12}\left(\frac{A}{N}\right)^{2}+\frac{b^{2}\left(N^{2}-1\right)}{3}
$$

Since we assume the prevailing equilibrium of the centralization game is the Pareto optimal equilibrium with $N=N(b, A)$, we may write the CEO's ex ante expected loss for this game as a function of the exogenous parameters $b$ and $A$ as

$$
L(b, A)=\frac{1}{12}\left(\frac{A}{N(b, A)}\right)^{2}+\frac{b^{2}\left(N(b, A)^{2}-1\right)}{3} .
$$

18 Although $A$ and $P$ are assumed to be the same for all projects of a given type for a given firm, these parameters may differ across firms for a given project type. 
Similarly, in the delegation game, the CEO's ex ante expected loss for the Pareto optimal equilibrium is given by

$$
\frac{1}{P} \sum_{i=1}^{N(b, P)} \int_{p_{i}}^{p_{i-1}}\left(\frac{p_{i-1}+p_{i}}{2}+b-p\right)^{2} d p=b^{2}+L(b, P) .
$$

Thus, the CEO prefers centralization if and only if $L(b, A) \leq b^{2}+L(b, P)$. The following result characterizes when this will be the case (all proofs not included in the text may be found in the appendix).

THEOREM 1. The CEO prefers centralization if and only if $P \geq P(A, b)$, where $P(A, b)$ is continuous and increasing in $A$, and for any $b, P(A, b)<A$.

Theorem 1 characterizes a boundary, $P=P(A, b)$, that separates the $(A, P)$ plane into two regions, one above the boundary for which the CEO chooses centralization and the other below the boundary for which she chooses delegation. Theorem 1 also shows that the boundary lies below the $45^{\circ}$ line and is upward sloping (see Figure 1). The fact that the boundary is below the $45^{\circ}$ line means that the CEO prefers delegation only when her information is less important than the division manager's. Centralization avoids the division manager's bias but will result in under-utilization of the division manager's information. Delegation results in under-utilization of the CEO's information and in a larger-than-optimal decision due to the division manager's bias. If the division manager's information is sufficiently more important, the net gain in information utilization outweighs the loss due to the division manager's bias.

The fact that the boundary in Theorem 1 is upward sloping implies that increases (decreases) in the importance of the division manager's (CEO's) information may cause the CEO to switch from centralization to delegation, but not the reverse. That is, the probability that the CEO chooses centralization decreases (weakly) with the importance of the division manager's information (from one to zero) and increases (weakly) with the importance of the CEO's information (from zero to one).

Dessein (2002) shows that when the CEO has no private information and $\tilde{a}$ is uniformly distributed, the CEO prefers delegation whenever the division manager's information is more important than his bias. Moreover, when the division manager's information is less important than his bias, the CEO prefers to make the decision herself, even though, in this case, the division manager will not convey any useful information. As Theorem 1 shows, that is not the case when the CEO also has private information, at least if $\tilde{p}$ is uniformly distributed. ${ }^{19}$ Thus our approach results in situations where the decision is centralized, but the division manager still plays a non-trivial role.

\footnotetext{
19 Dessein's result does seem to hold if $p$ is binomial. In that case, the delegation equilibrium involves either no communication or full revelation. If there is full revelation, the agent chooses his full-information ideal point as in Dessein (2002). Although the CEO's private information makes
} 


\section{Centralization and Delegation Regions}

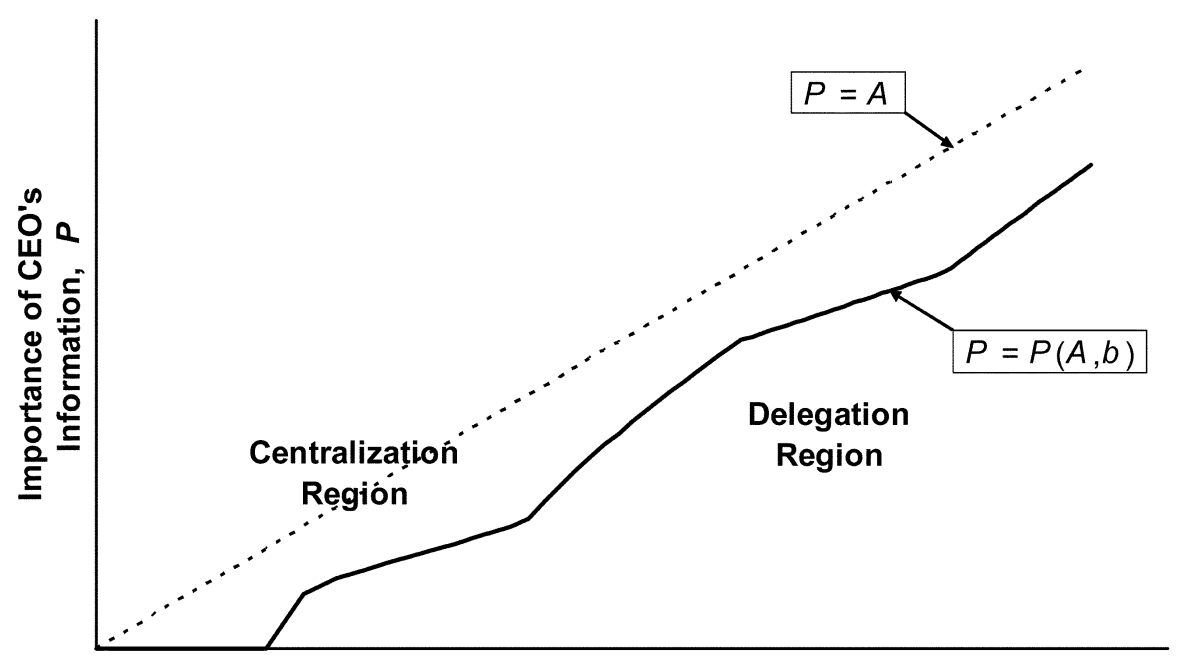

Importance of Manager's Information, $\boldsymbol{A}$

Figure 1. Regime choice as a function of $A$ and $P$.

\subsection{ASSIGNMENT BASED ON PROJECT SPECIFICS (THE ex post ENVIRONMENT)}

In this environment, we assume that the CEO chooses the regime after observing her private information. As mentioned above, in the delegation game, the CEO's report contains more information when $p$ is large than when it is small. This would seem to give delegation an advantage when $p$ is large. Consequently, we propose an equilibrium in which the CEO chooses delegation when $p$ is above a cut-off level and centralization when $p$ is below this level. ${ }^{20}$ Formally, we have

THEOREM 2. There exists a cut-off level of $p, p^{*} \in[0, P]$, such that the following set of strategies and beliefs constitute a Perfect Bayesian Equilibrium of the decision assignment game when this assignment is made by the CEO after observing $p$ :

- The CEO chooses delegation with probability one if $p \geq p^{*}$ and chooses centralization with probability one if $p<p^{*}$. If the CEO chooses delegation,

the equilibrium of the centralization game different in our model from that of Dessein, one might conjecture that, whenever delegation involves full-revelation, Dessein's result would hold. For the examples we have calculated, the CEO prefers centralization only when delegation involves no communication. This occurs only when the bias is sufficiently large that centralization also involves no communication.

20 Although we do not show that this is the only equilibrium, it can be shown that there is no equilibrium in which the CEO chooses delegation for low values of $p$ and centralization for high values. 
she reports according to the delegation-game equilibrium of Section 3 for $\tilde{p} \in$ $\left[p^{*}, P\right]$. If she chooses centralization, her beliefs and strategies are as in the centralization-game equilibrium of Section 3.

- If the CEO chooses delegation and reports $r \geq p^{*}$, the division manager plays according to the delegation-game equilibrium of Section 3 for $\tilde{p} \in\left[p^{*}, P\right]$. If the CEO chooses delegation and reports $r<p^{*}$, the division manager infers that $\tilde{p} \in\left[p_{N-1}, p_{N}\right],{ }^{21}$ where $\left\{p_{i}\right\}_{i=1}^{N}$ is the equilibrium partition of Section 3 for the delegation game in which $\tilde{p} \in\left[p^{*}, P\right]$ with $N=N\left(b, P-p^{*}\right)$. The division manager then chooses $y$ as in the equilibrium of the delegation game in Section 3, given these beliefs, i.e., $y=\left(p_{N-1}+p_{N}\right) / 2+a+b$. If the CEO chooses centralization, the division manager plays as in the centralization-game equilibrium of Section 3 for $\tilde{p}$ uniformly distributed on $\left[0, p^{*}\right]$.

Intuitively, as the importance of the division manager's information or his informational advantage increases, delegation becomes more attractive. One might, therefore, expect that increases in $A$ reduce the cutoff level for $p, p^{*}$, above which the CEO will delegate. Conversely, increases in the importance of the CEO's information or in her informational advantage would seem to make delegation less attractive. Thus, one might expect that increases in $P$ increase $p^{*}$. Both results are, in fact, true, and, in addition, it can be shown that the probability of centralization also decreases with increases in $A$ and increases with increases in $P$. These results are summarized in the following corollary.

COROLLARY TO THEOREM 2 . The cutoff level, $p^{*}$, and the probability that the CEO chooses centralization, $p^{*} / P$, are decreasing in $A$ and increasing in $P$.

The behavior of the likelihood of choosing delegation for a project type with respect to $A$ and $P$ is similar to the case in which the CEO chooses whether to delegate before observing the project specifics, although, in that case, the probability of delegation given the project type is either zero or one.

\subsection{COMPARISON OF ex ante AND ex post ENVIRONMENTS}

An interesting question raised by our analysis of the two environments is the following. Suppose the CEO could decide either to commit to an allocation of authority ex ante (before observing her private information) or choose the allocation ex post. Would she ever choose to commit ex ante? The advantage of the ex post allocation is that it can be based on the CEO's private information, so that the CEO will delegate in those situations where her information is more completely communicated. The disadvantage of this environment is that the allocation decision

\footnotetext{
21 The agent could infer that $\tilde{p}$ is in any cell of the partition $\left\{p_{i}\right\}$ without affecting the result.
} 
itself conveys information, making it more difficult for the CEO to control the amount of information that she communicates to the division manager.

It turns out that the CEO would never commit to centralize ex ante, if she were allowed to make the delegation decision ex post. When the CEO's information is not very important, i.e., $P$ is small, however, the CEO is indeed better off committing to delegate ex ante. On the other hand, when the CEO's information is sufficiently important, she strictly prefers not to commit to delegate ex ante. The result is summarized formally in Theorem 3 .

THEOREM 3. If the CEO can commit to an allocation of authority ex ante but is not forced to do so, she will never commit to centralization ex ante. Given $A$ and $b$, there is a threshold, $\bar{P}(b, A)$, such that the CEO will not commit to delegation whenever $P>\bar{P}(b, A)$ but will commit to delegation for sufficiently small values of $P<\bar{P}(b, A)$.

This completes our analysis of the CEO's assignment of decision-making authority. We now turn to the empirical implications of our results.

\section{Empirical Implications}

The endogenous variables in our model are the choice of regime, centralization or delegation, the investment, $y$, and the amount of information transmitted in either regime. Since the amount of information transmitted is likely to be largely unobservable in practice, we focus on the other two endogenous variables.

The choice of regime depends on three exogenous parameters of the model, $P$, $A$, and $b$. Recall from the introduction that the parameters, $P$ and $A$, have the dual interpretations as the importance of the CEO's (division manager's) information and as the informational advantage of the CEO (division manager) with regard to the CEO's (division manager's) private information.

Our main empirical results can be summarized as follows.

- Increases in the importance of the CEO's information increase the probability of centralization, and increases in the importance of the division manager's information decrease the probability of centralization.

- Increases in agency problems can result in more delegation (not less as might be thought).

- Types of projects in which the CEO's information is more important and/or the division manager's information is less important are more likely to be centralized. Some examples in which centralization is more likely are new plant decisions relative to decisions involving plant expansion, decisions regarding major new product initiatives relative to decisions involving expansions of existing products, decisions to expand into new geographical markets relative to decisions involving expansion of existing markets, decisions to acquire other 
firms relative to decisions to undertake internal investments, heavily regulated projects relative to less regulated project, and projects in which the span of control of upper level management is narrower.

- Even though the division manager is biased toward larger investments, if the bias is not too large, investments approved at a higher level are larger on average than those approved at a lower level. ${ }^{22}$ Controlling for project type and firm, however, investments approved at a higher level are smaller on average than those approved at a lower level.

- The CEO has an incentive to reduce informational advantage, both her own and that of the division manager. This can be accomplished by selecting project types for which information is more symmetric and by creating a more transparent environment.

- The division manager, on the other hand, in some situations, has an incentive to increase his own informational advantage, either by steering the CEO toward project types for which this is the case, or by reducing the transparency of the environment, or both.

The first bullet point is discussed in the previous section. The remainder of this section develops and discusses the other implications.

\subsection{INCREASE IN AGENCY PROBLEMS MAY INCREASE DELEGATION}

Suppose the decision assignment is based on project type and consider the effect of the preference bias, $b$, on regime choice. The boundary between the centralization and delegation regions, $P(A, b)$, is, in general, not monotone in $b$, as the example depicted in Figure 2 shows. In particular, for some parameter values, an increase in the division manager's bias, $b$, can result in more delegation, not less. This, somewhat counterintuitive, result is due to the fact that the extent of communication is affected by the bias differentially in the two regimes. Thus, an increase in the bias, while making the division manager's choice less attractive to the CEO, can also decrease the extent to which the division manager will communicate his information in the centralization game more than in the delegation game. In this case, the increase in the division manager's bias has two opposing effects: it increases the distortion in his decision, but it also reduces communication when the decision is centralized relative to that when it is delegated. The net effect, as seen in the example, can result in switching from centralization to delegation when the division manager's bias increases. The simple intuition is wrong because it ignores the second effect. Also, note that this prediction differs from that of Dessein (2002). In particular in Dessein's model, where the second effect is missing, increases in the division manager's bias (weakly) reduce delegation.

22 This is consistent with the observations of Taggart (1987) and Ross (1986). 
The Function $P(A, b)$

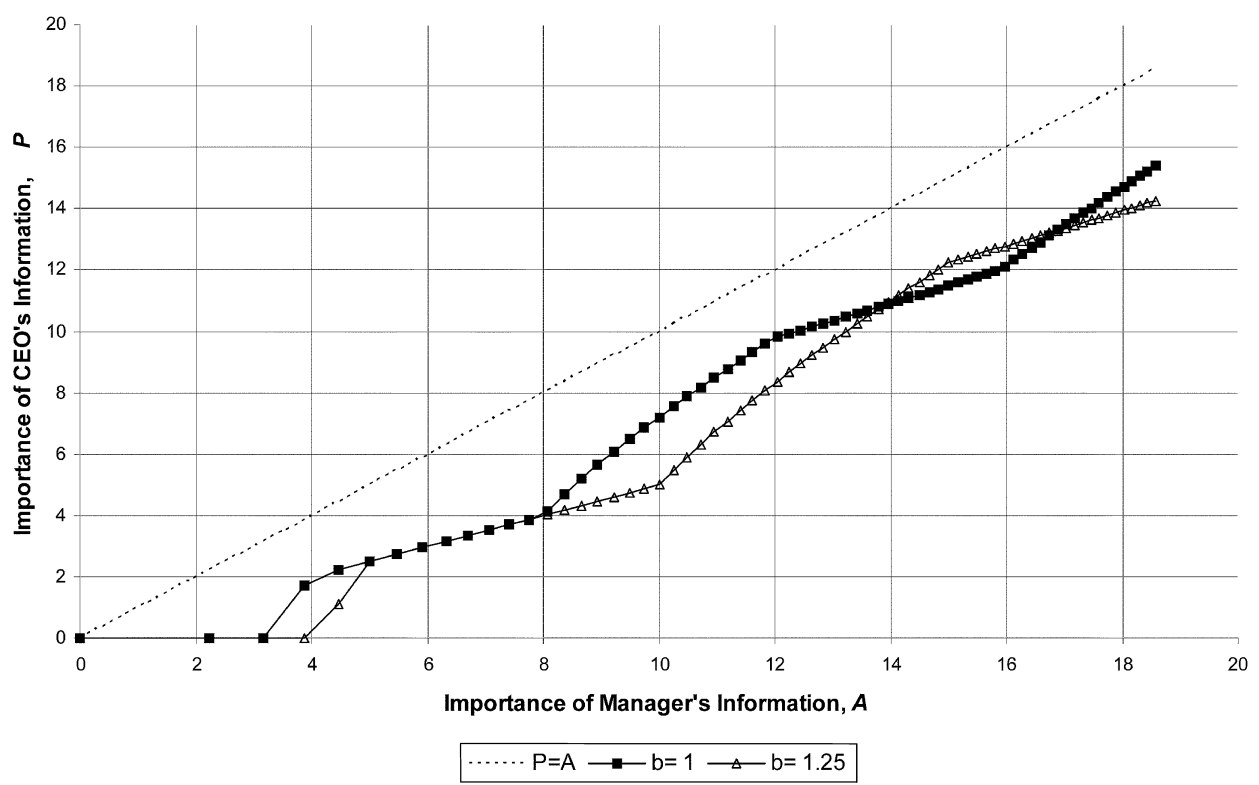

Figure 2. $P(A, b)$ for two values of $b$.

\subsection{THE EFFECT OF PROJECT TYPE ON REGIME CHOICE}

Consider two project types say 1 and 2 and a sample of regime choices for these two project types for various firms. Suppose that the CEO's information is more important for type-1 projects, while the division manager's information is more important for type- 2 projects.

First, suppose that the decision assignment is based on project type. Since the boundary in the $(A, P)$ plane that separates the centralization region (above the boundary) from the delegation region (below the boundary) is upward sloping, a larger fraction of type- 1 projects will be centralized than type- 2 projects, or, viewing these fractions as probabilities,

$\operatorname{Pr}($ Centralization $\mid$ type-1 $)>\operatorname{Pr}($ Centralization | type-2)

Now consider the case where the decision assignment is made on a project-byproject basis (i.e., after observing $p$ ). In this environment, as shown in the Corollary to Theorem 2, the probability of centralization is increasing in $P$ and decreasing in $A$. Since type-1 projects have smaller values of $A$ and larger values of $P$ than type- 2 projects, the corollary implies that type- 1 projects are more likely to be centralized than type-2 projects, i.e., condition (8) holds for this environment as well.

For the examples mentioned in the third bullet point above, we contend that the information of upper level management is more important and that of lower level 
managers is less important for the projects for which we claim centralization is more likely.

\subsection{PROJECT SIZE AND THE ALLOCATION OF AUTHORITY}

We turn now to the issue of the relation between where in the firm decisions are made and project size. There are two aspects of this issue. Taggart's (1987) results suggest that the allocation of decision-making authority is sometimes based on expected or projected investment, with projects having larger projected investments being approved at higher levels in the firm. Ross's (1986) observations suggest that the average realized investment is positively associated with level. We consider first the use of expected investment in decision assignment rules.

Consider the environment in which the assignment is based on project type. In this environment, the decision assignment is driven by the informational characteristics of the project types and the extent of agency problems, not by projected investment per se. It may be the case, however, that, among the types of projects normally undertaken by a given firm, those that fall in the centralization region have larger expected ideal expenditure than those that fall in the delegation region. This would be the case, for example, if the firm normally undertakes only projects of types 1 and 2 as described above, and projects of type 1 have larger expected ideal investment (we will argue below that such an assumption is reasonable). In this case, a simple way of implementing the optimal decision assignment rule is to centralize all projects with expected investment above a certain level and delegate the rest. Thus our model can rationalize a rule that assigns decisions for projects with larger projected investment to higher levels.

We now turn to the positive association between average realized investment and the level at which the decision is made. In particular, we argue that project types in which the CEO's information is more important and the division manager's information is less important than other project types will, on average, involve larger investments, i.e., that type- 1 projects are larger on average than type- 2 projects. For example, new-plant projects should involve larger investment on average than plant-expansion projects. Formally, we relax the assumption that the supports of $\tilde{p}$ and $\tilde{a}$ start at zero (but the parameters $A$ and $P$ still refer to the width of the supports). We assume instead that

$$
\bar{y}_{1}>\bar{y}_{2},
$$

where $\bar{y}_{t}$ is the expected first-best investment for a project of type $t$ (either 1 or 2).

Now consider expected investment as a function of regime. The expected investments for delegation, $D$, and centralization, $C$, are

$$
E(\tilde{y} \mid D)=b+\sum_{t \in\{1,2\}} \bar{y}_{t} \operatorname{Pr}(t \mid D) \text { and }
$$




$$
E(\tilde{y} \mid C)=\sum_{t \in\{1,2\}} \bar{y}_{t} \operatorname{Pr}(t \mid C)
$$

respectively. Therefore,

$$
E(\tilde{y} \mid C)-E(\tilde{y} \mid D)=\left(\bar{y}_{1}-\bar{y}_{2}\right)[\operatorname{Pr}(t=1 \mid C)-\operatorname{Pr}(t=1 \mid D)]-b .
$$

But, it is easy to check that Bayes' Rule and (8) imply that

$$
\operatorname{Pr}(t=1 \mid C)>\operatorname{Pr}(t=1 \mid D) .
$$

Consequently, (9) implies that $\left(\bar{y}_{1}-\bar{y}_{2}\right)[\operatorname{Pr}(t=1 \mid C)-\operatorname{Pr}(t=1 \mid D)]>0$. We have shown, regardless of whether the decision assignment depends on project type or is made on a project-by-project basis (since (8) holds for both environments), that despite the fact that the division manager is biased toward larger expenditure, if his bias is not too large, delegated projects will involve smaller investment on average than centralized projects.

Note that, in the above result, we do not control for project type or firm. That is, we expect the result to hold for a sample of firms considering projects of both types. Controlling for project type and firm reverses the conclusion if the decision assignment is based on project specifics. In that case, the model implies that expected investment for centralized projects, of a given type and firm, will be smaller than that for delegated projects of that type for that firm. There are two reasons for this. First, expected investment conditional on the CEO's information, $p$, is increasing in $p$, for a given project type, and, when the assignment is based on project specifics, projects with larger values of $p$ are delegated. Second, investment in delegated projects will be larger than investment in centralized projects because of the division manager's bias toward larger expenditure. Thus our model predicts that when authority is allocated based on project specifics, for a given project type and for a given firm, average investment in delegated projects should be larger than in centralized projects.

\subsection{PROJECT SELECTION}

Our model also has some implications for project selection. The CEO's derived preferences for different types of projects, i.e., values of $b, P$ and $A$, for each regime are given in Equations (6) and (7) above, i.e., her expected loss in the centralization regime is $L(b, A)$ and in the delegation regime is $b^{2}+L(b, P)$. The division manager's expected losses are, by symmetry, $b^{2}+L(b, A)$ in centralization and $L(b, P)$ in delegation.

Since the loss function $L$ is increasing in its second argument (see Lemma 1 in the appendix), given a regime, either party, to the extent that she or he cares about the parties' informational advantages (or the importance of their information), prefers greater informational symmetry, i.e., smaller values of $P$ and $A$ (of 
course, both parties care about $P$ only under delegation and about $A$ only under centralization). Changes in $A$ and $P$, however, may also shift the regime and so affect preferences indirectly. Consequently, we must analyze the parties' preferences for project types more carefully.

For this exercise we focus on the environment in which the decision assignment is based on project type and ask whether either party has an incentive to promote projects with greater informational asymmetry. As mentioned, this can only be the case if the difference in informational asymmetry causes a difference in regime. First, consider two project types characterized by $(A, P)$ and $\left(A^{\prime}, P\right)$, with $A<A^{\prime}$ and where the $\mathrm{CEO}$ chooses centralization for $(A, P)$ but delegation for $\left(A^{\prime}, P\right)$. We claim that, in this case, the CEO prefers projects of type $(A, P)$ to those of type $\left(A^{\prime}, P\right)$. The fact that the CEO chooses centralization for $(A, P)$ implies $L(b, A)<$ $b^{2}+L(b, P)$. This inequality, however, implies that the CEO prefers $(A, P)$ to $\left(A^{\prime}, P\right)$, since both project types have the same value of $P$, and the CEO's loss when the decision is delegated does not depend on $A$.

Now consider two project types characterized by $(A, P)$ and $\left(A, P^{\prime}\right)$, with $P<$ $P^{\prime}$ and where the CEO chooses delegation for $(A, P)$ but centralization for $\left(A, P^{\prime}\right)$. We claim that, in this case, the CEO prefers projects of type $(A, P)$ to those of type $\left(A, P^{\prime}\right)$. The fact that the CEO chooses delegation for $(A, P)$ implies $L(b, A)>$ $b^{2}+L(b, P)$. This inequality, however, again implies that the CEO prefers $(A, P)$ to $\left(A, P^{\prime}\right)$, since both project types have the same value of $A$, and the CEO's loss when the decision is centralized does not depend on $P$. Thus we see that the CEO always prefers more informational symmetry, even if this affects the regime.

Now consider the division manager. He will prefer $(A, P)$ to $\left(A, P^{\prime}\right)$ if and only if $L(b, A)+b^{2}>L(b, P)$. The fact that the CEO prefers to delegate the decision for projects of type $(A, P)$ implies this inequality, however. Thus, the division manager prefers project types in which the CEO's informational advantage is smaller or her information is less important. Intuitively, to the extent that a decrease in the CEO's informational advantage shifts the regime, it shifts it toward delegation. Since the division manager prefers delegation whenever the CEO does, such a decrease benefits the division manager.

Finally, the division manager will prefer $\left(A^{\prime}, P\right)$, which involves delegation, to $(A, P)$, which involves centralization, if and only if $L(b, P)<b^{2}+L(b, A)$. This, however, is exactly the condition under which the division manager would prefer that the decision be delegated for projects of type $(A, P)$. It is easy to check that there are project types $(A, P)$ for which the CEO prefers centralization, but the division manager prefers delegation. ${ }^{23}$ Thus, it is possible for the division manager to prefer that his informational advantage be larger or his information be more important. In particular, the division manager has an incentive to promote types of projects in which this is the case over other types of projects if two conditions are satisfied. First, the project types for which the division manager's information is less important must be such that the division manager prefers delegation while the

23 The required condition is $L(b, A)-b^{2}<L(b, P)<L(b, A)+b^{2}$. 
CEO prefers centralization. Second, the project types for which the division manager's information is more important must be such that the CEO prefers delegation. Intuitively, the increase in $A$ is beneficial for the division manager if the division manager prefers delegation to begin with and the increase in $A$ causes the CEO to switch from centralization to delegation.

In summary, the $\mathrm{CEO}$ has an incentive to reduce informational advantage, both her own and that of the division manager. She may do this by selecting project types for which information is more symmetric or by creating a more transparent environment. The division manager, on the other hand, may have an incentive to increase his own informational advantage, either by steering the CEO toward project types for which this is the case, or by reducing the transparency of the environment.

\section{Other Regimes}

Thus far we have not considered regimes other than centralization and delegation. Although these are the most commonly observed allocations of decision-making authority, others are possible. In this section, we consider whether there are regimes in which both parties are, ex ante, better off than in either the centralization or delegation regimes. Such regimes might include, for example, multiple stages of message exchange or allocating decision-making authority as a function of messages from both parties. Such regimes cannot Pareto-dominate the two we considered above if the reporting party (the party not making the final decision) can predict for sure what the decision-maker will do as a function of the reporter's messages, as is shown in the following theorem due to Krishna and Morgan (2004).

THEOREM 4. [Krishna and Morgan (2004)]. Any regime in which the CEO has authority to choose the investment size and in which the division manager can predict his own utility for sure as a function of the division manager's sequence of plays, yields the same set of equilibrium outcomes as the centralization game. Similarly, any regime in which the division manager has authority to choose the investment size and in which the CEO can predict her own utility for sure as a function of the CEO's sequence of plays, yields the same set of equilibrium outcomes as the delegation game. ${ }^{24}$

For regimes in which the $\mathrm{CEO}$ has authority to choose the investment size but in which the division manager cannot predict his own utility for sure as a function of the division manager's sequence of plays, it turns out that the centralization game

\footnotetext{
24 Our situation is exactly the same as that of Krishna and Morgan (2004), except that, in our case, both parties have private information. As argued in Section 3, however, both centralization and delegation can be reduced to the Crawford-Sobel (1982) set-up. The same argument applies to any game in which one party has the authority to choose the investment size. Since this is the set-up used by Krishna and Morgan (2004), their argument applies. A symmetric argument applies to any game in which the division manager chooses the investment size.
} 
can be improved on (and a similar statement holds for delegation) as is shown by example in Krishna and Morgan (2004). ${ }^{25}$

Although the Krishna-Morgan example shows that centralization (and similarly delegation) can be improved upon, the regimes needed to achieve the improvement involve randomization of a sort we generally do not observe in practice. Without such randomization, Theorem 4 shows that our consideration of centralization and delegation is without loss of generality. Moreover, since these are the simplest examples of the types of games assumed in Theorem 4, it is not surprising that these are the most commonly observed.

\section{Conclusions}

In this paper we present a simple model based on bilateral private information to understand what determines when a CEO will make an investment decision herself, based on her own information and information communicated by a division manager, and when she will allow the division manager to make the decision, based on his own information and information communicated by the CEO. When the decision assignment is based on project type, we show that delegation will occur only when the division manager has a sufficiently greater informational advantage over his private information than does the CEO over hers or the division manager's information is sufficiently more important. When the decision assignment is on a project-by-project basis, we show that the CEO will delegate when the ideal investment is likely to be large and therefore more in line with the division manager's preference bias. In either case, across a sample of firms, the probability of delegation is increasing in the importance of the division manager's private information and decreasing in the importance of the CEO's private information. Moreover, we characterize situations in which the CEO prefers to commit to an allocation of authority ex ante, instead of deciding based on her private information.

We also show that, even though the division manager is biased toward larger investments, under certain conditions, the average investment will be smaller when the decision is delegated. This helps explain some findings in the empirical literature. Finally, we show the somewhat counterintuitive result that, in some circumstances, increases in the division manager's bias result in increased willingness of the CEO to delegate the decision. A number of empirical implications are developed.

There are (at least) three issues that we have not addressed. First is the effects of endogenous information acquisition. With endogenous information acquisition one can investigate whether committing to a regime affects the amount of information generated and, if so, whether this in turn affects the determination of the regime.

Second, we have not considered more than two levels of hierarchy. With more than two levels of hierarchy, additional channels of communication become available. For example, the CEO could communicate directly with managers two or

\footnotetext{
25 See Aumann and Hart (2003) for a similar idea.
} 
more levels below. If she depends on managers directly below her to transmit her communication with them to managers below them, presumably there would be additional loss of information. This raises the issue of why upper level managers often do not choose to communicate directly with managers at lower levels in the firm and how the availability of additional channels interacts with the allocation of decision-making authority.

Third, rather than analyzing optimal incentive contracts in this setting explicitly, we have simply assumed reduced-form utility functions for the two parties. Analyzing incentive contracts could produce interesting results regarding both contracts and the allocation of decision-making authority.

\section{Appendix}

The formal statement of the equilibrium conditions for centralization is:

$\forall a \in[0, A]$, if $r^{*}$ is in the support of $q(\cdot \mid a)$, then

$r^{*} \in \underset{r}{\arg \min } E\left(y^{*}(\tilde{p}, r)-\tilde{p}-a-b\right)^{2}$,

for each $r, p, y^{*}(p, r) \in \underset{y}{\arg \min } \int_{0}^{A}(y-p-a)^{2} g(a \mid r) d a$,

for each $r$ in the support of $q(\cdot \mid a)$ for some $a \in[0, A], g(a \mid r)$

$$
=\frac{q(r \mid a)}{\int_{0}^{A} q(r \mid t) d t} .
$$

The formal statement of the reduced form version of (12) is

If $r^{*}$ is in the support of $q(\cdot \mid a)$, then $r^{*} \in \underset{r}{\arg \min }(\bar{a}(r)-a-b)^{2}$.

Since, in equilibrium, the division manager draws $r_{i}$ from a uniform distribution on $\left[a_{i-1}, a_{i}\right]$, (14) implies that the CEO's posterior belief about $a$, conditional on the division manager's report, is uniform on $\left[a_{i-1}, a_{i}\right]$, and

$$
\bar{a}(r)=\frac{a_{j-1}+a_{j}}{2}, \text { for any } r \in\left[a_{j-1}, a_{j}\right] \text { and any } j \in\{1, \ldots, N\} .
$$

The formula for $N(b, A)$, derived in Crawford and Sobel (1982, p. 1441) is $N(b, A)=\langle\hat{N}(b, A)-1\rangle$, where $\langle x\rangle$ denotes the smallest integer greater than or equal to $x$ and

$$
\hat{N}(b, x)(\hat{N}(b, x)-1)=\frac{x}{2 b} \text { or } \hat{N}(b, x)=\frac{1+\sqrt{1+2 x / b}}{2}, \text { for } x>0 .
$$


An additional piece of notation will be useful. Define, for any $x \geq 0$,

$$
l(N, b, x)=\frac{1}{12}\left(\frac{x}{N}\right)^{2}+\frac{b^{2}\left(N^{2}-1\right)}{3} .
$$

Thus, $L(b, x)=l(N(b, x), b, x)$.

LEMMA 1. $L(b, x)$ is continuous and increasing in $x$. Also, for any $x>0, b^{2} \geq$ $L(b, x)$ if and only if $b \geq \sigma(x)$, where $\sigma(x)=x / \sqrt{12}$ is the standard deviation of a random variable that is uniformly distributed on an interval of width $x$.

Proof. Define $x_{n}$ to be the value of $x$ at which $N(b, x)$ jumps from $n-1$ to $n$. At such a point, $\hat{N}\left(b, x_{n}\right)=n$ (and $\left.N\left(b, x_{n}\right)=n-1\right)$, or $x_{n}=2 b n(n-1)$, for $n=1,2, \ldots$. It is easy to show that

$$
l\left(N\left(b, x_{n}\right), b, x_{n}\right)=\frac{2}{3} b^{2} n(n-1)=l\left(N\left(b, x_{n}\right)+1, b, x_{n}\right) .
$$

Thus $l(N(b, x), b, x)$ is continuous in $x$ (despite the fact that $N(b, x)$ is not) and

$$
l(N(b, x), b, x)=l(n, b, x), \text { for } x \in\left[x_{n}, x_{n+1}\right]
$$

Also, since $l(n, b, x)$ is increasing in $x$ (for fixed $n)$ and $l(N(b, x), b, x)$ is continuous in $x$, it follows that $l(n(b, x), b, x)$ is increasing in $x$.

Finally, the above argument implies that $L\left(b, x_{2}\right)=4 b^{2} / 3>b^{2}$. Therefore, if $x$ is such that $b^{2} \geq L(b, x)$, then $x<x_{2}$. On the other hand, if $b \geq \sigma(x)$, then $x \leq(2 \sqrt{3}) b<4 b=x_{2}$. Thus, in either case, $N(b, x)=1$, so $L(b, x)=\sigma^{2}(x)$. Consequently, $b^{2} \geq L(b, x)$ if and only if $b \geq \sigma(x)$.

THEOREM 1. The CEO prefers centralization if and only if $P \geq P(A, b)$, where $P(A, b)$ is given by

$$
P(A, b)= \begin{cases}{\left[\left(\frac{n-1}{n} A\right)^{2}+8(n-1)^{2}(n-2) b^{2}\right]^{1 / 2}} & \text { if } A \in\left[x_{n}, \hat{x}_{n}\right] \\ {\left[A^{2}-12 n^{2} b^{2}\right]^{1 / 2}} & \text { if } A \in\left[\hat{x}_{n}, x_{n+1}\right]\end{cases}
$$

for $n=N(b, A)$, where $\hat{x}_{N(b, A)}$ is defined by (21) (below). Moreover, $P(A, b)$ is continuous and increasing in $A$, and for any $b, P(A, b)=0$ for $A \in\left[0, \hat{x}_{1}\right]$, and, for all $A \geq \hat{x}_{1}, P(A, b) \leq\left[\max \left\{A^{2}-12 b^{2}, 0\right\}\right]^{1 / 2}$. In particular $P(A, b)<A$, for all $b$.

Proof. Define $\hat{x}_{n}$ to be such that the CEO is indifferent between centralization with $A=\hat{x}_{n}$ and delegation with $P=x_{n}$. Assume that $x_{n}<\hat{x}_{n}<x_{n+1}$ (this will be verified below). Then, using (6) and (7), $\hat{x}_{n}$ satisfies $b^{2}+l\left(n-1, b, x_{n}\right)=$ $l\left(n, b, \hat{x}_{n}\right)$. Solving for $\hat{x}_{n}$ using (19) and (20) yields

$$
\hat{x}_{n}=2 b n\left(n^{2}-2 n+4\right)^{1 / 2} \text {. }
$$


It is now easy to check that $x_{n}<\hat{x}_{n}<x_{n+1}$.

Suppose $A \in\left[x_{n}, \hat{x}_{n}\right]$ and $P$ is such that the CEO is indifferent between centralization and delegation. Then $P$ must satisfy $b^{2}+l(n-1, b, P)=l(n, b, A)$. It follows that

$$
P=\left[\left(\frac{n-1}{n} A\right)^{2}+8(n-1)^{2}(n-2) b^{2}\right]^{1 / 2} .
$$

Now suppose $A \in\left[\hat{x}_{n}, x_{n+1}\right]$ and $P$ is such that the CEO is indifferent between centralization and delegation. In this case, $P$ must satisfy $b^{2}+l(n, b, P)=$ $l(n, b, A)$. It follows that

$$
P=\left[A^{2}-12 n^{2} b^{2}\right]^{1 / 2} .
$$

Combining (22) and (23), results in $P(A, b)$ given in the statement of the theorem.

Using (6) and (7), the CEO prefers centralization if and only if $L(b, A) \leq b^{2}+$ $L(b, P)$. But, by definition of $P(A, b), L(b, A)=b^{2}+L(b, P(A, b))$. Combining these two and using Lemma 1 implies the formula in the statement of the theorem.

Continuity is easy to check. Since $P(A, b)$ is increasing in $A$ on each segment and is continuous, it is increasing. That $P(A, b) \leq\left[\max \left\{A^{2}-12 b^{2}, 0\right\}\right]^{1 / 2}$ is obvious for $A \in\left[\hat{x}_{n}, x_{n+1}\right]$ for some $n$ and for $A \in\left[x_{1}, \hat{x}_{1}\right]$. Suppose $A \in\left[x_{n}, \hat{x}_{n}\right]$ for some $n \geq 2$. Then it suffices to show that

$$
8 b^{2}(n-1)^{2}(n-2)+12 b^{2} \leq \frac{2 n-1}{n^{2}} A^{2}, \forall A \in\left[x_{n}, \hat{x}_{n}\right] .
$$

But, since $2 n-1>0$, it suffices to show the inequality for $A=x_{n}$. The result follows by substitution.

Q.E.D.

THEOREM 2. There exists a cut-off level of $p, p^{*} \in[0, P]$, such that the following set of strategies and beliefs constitute a Perfect Bayesian Equilibrium of the decision assignment game when this assignment is made by the CEO after observing $p$ :

- The CEO chooses delegation with probability one if $p \geq p^{*}$ and chooses centralization with probability one if $p<p^{*}$. If the CEO chooses delegation, she reports according to the delegation-game equilibrium of Section 3 for $\tilde{p} \in$ $\left[p^{*}, P\right]$. If she chooses centralization, her beliefs and strategies are as in the centralization-game equilibrium of Section 3.

- If the CEO chooses delegation and reports $r \geq p^{*}$, the division manager plays according to the delegation-game equilibrium of Section 3 for $\tilde{p} \in\left[p^{*}, P\right]$. If the CEO chooses delegation and reports $r<p^{*}$, the division manager infers that $\tilde{p} \in\left[p_{N-1}, p_{n}\right]$, where $\left\{p_{i}\right\}_{i=1}^{N}$ is the equilibrium partition of Section 3 for the delegation game in which $\tilde{p} \in\left[p^{*}, P\right]$ with $N=N\left(b, P-p^{*}\right)$. The division manager then chooses $y$ as in the equilibrium of the delegation 
game in Section 3, given these beliefs, i.e., $y=\left(p_{N-1}+p_{n}\right) / 2+a+b$. If the $\mathrm{CEO}$ chooses centralization, the division manager plays as in the centralization-game equilibrium of Section 3 for $\tilde{p}$ uniformly distributed on $\left[0, p^{*}\right]$.

Proof. First, fix an arbitrary value for $p^{*}$ and assume the division manager believes that the CEO behaves as described in the statement of the theorem (we will compute the correct value of $p^{*}$ below). Clearly, if the CEO chooses centralization, or she chooses delegation and reports $r \geq p^{*}$, the division manager's behavior as described in the statement of the theorem constitutes a best response, and his beliefs satisfy Bayes' rule as in Section 3. Also, since the CEO choosing delegation and reporting $r<p^{*}$ is not on the equilibrium path, the division manager's beliefs after such an event need not satisfy Bayes' rule. Moreover, the division manager's choice of $y$ is a best response given the postulated beliefs as shown in Section 3 . Therefore, it remains only to show that $p^{*}$ exists such that

- If $p \geq p^{*}$ and the division manager plays as assumed, the CEO prefers delegation and, given that she chooses delegation, prefers to play the subgame according to the equilibrium of Section 3 , and

- If $p<p^{*}$ and the division manager plays as assumed, the CEO prefers centralization.

For any $p^{*}$, if the division manager plays as assumed and $p \geq p^{*}$, if the CEO chooses delegation and plays the proposed equilibrium strategy, her (expected) loss is given by

$$
\left[\frac{p_{i(p)-1}+p_{i(p)}}{2}+b-p\right]^{2}
$$

where, $\forall i \in\{1, \ldots, N\}$ (with $N=N\left(b, P-p^{*}\right)$ ),

$$
p_{i}=\frac{i P+(N-i) p^{*}}{N}+2 i(N-i) b,
$$

and $i(p)$ is such that $p \in\left[p_{i(p)-1}, p_{i(p)}\right]$.

If, on the other hand, the CEO chooses delegation and reports any $r \notin$ $\left[p_{i(p)^{-1}}, p_{i(p)}\right]$, including $r<p^{*}$, her loss is given by

$$
\left[\frac{p_{i-1}+p_{i}}{2}+b-p\right]^{2}
$$

for some $i$. Clearly, (26) (weakly) exceeds (24) since, by construction of the partition $\left\{p_{i}\right\}_{i=1}^{N}$, the CEO prefers the division manager to believe that $p \in$ $\left[p_{i(p)-1}, p_{i(p)}\right]$ as opposed to believing that $p \in\left[p_{i-1}, p_{i}\right]$ for any other $i$. Therefore, we have shown that if the CEO chooses delegation when $p \geq p^{*}$, she prefers 
to play the proposed equilibrium strategy instead of reporting any other value for $p$.

If the CEO chooses centralization, her loss is given by $L(b, A)$. It is easy to check, using (25), that (24) is maximized over $p \in\left[p^{*}, P\right]$ at $p=p^{*}$. Therefore, it suffices to show

$$
f\left(b, P-p^{*}\right) \equiv\left(\frac{P-p^{*}}{2 N\left(b, P-p^{*}\right)}+N\left(b, P-p^{*}\right) b\right)^{2} \leq L(b, A) .
$$

It follows that we must choose $p^{*}$ to satisfy (27).

Now suppose $p<p^{*}$. If the CEO chooses centralization, her expected loss is the same as before, namely $L(b, A)$. If, contrary to the proposed equilibrium, she chooses delegation, it is easy to check that her optimal report is $r=p^{*}$. In that case, her expected loss is given by

$$
\left[\frac{P+(2 N-1) p^{*}}{2 N}-p+N b\right]^{2}
$$

where $N=N\left(b, P-p^{*}\right)$. It is easy to check that the expression in (28) is decreasing in $p$ over the range $p \leq p^{*}$. Therefore, to show that the CEO prefers the proposed equilibrium strategy of centralization in this case, we need only show that this expression exceeds $L(b, A)$ at $p=p^{*}$. At $p=p^{*}$, however, the expression in (28) is equal to $f\left(b, P-p^{*}\right)$. Thus, we must show that the reverse inequality from (27) holds for $p<p^{*}$. Using the same technique as in Lemma 1, it can be shown that $f\left(b, P-p^{*}\right)$ is continuous in $p^{*}$. Since it is decreasing in $p^{*}$ for fixed $N$ and continuous, it is decreasing in $p^{*}$. Therefore, if we define $p^{*}$ as the value that makes $f\left(b, P-p^{*}\right)=L(b, A)$, (27) holds for $p \geq p^{*}$, and the reverse inequality holds for $p<p^{*}$ as required. If no such value exists, then either $f(b, P) \leq L(b, A)$, in which case we can define $p^{*}=0$ (and the CEO prefers always to delegate), or $b^{2} \geq L(b, A)$, or equivalently, $b \geq \sigma(A)$, in which case we can define $p^{*}=P$ (and the CEO prefers always to centralize).

Q.E.D.

COROLLARY TO THEOREM 2 . The cutoff level, $p^{*}$, and the probability that the CEO chooses centralization, $p^{*} / P$, are decreasing in $A$ and increasing in $P$.

Proof. Using Lemma 1 and the fact that the left hand side of (27) is decreasing in $p^{*}$, we see that $p^{*}$ is decreasing in $A$. Also, the left hand side of (27) is increasing in $P$, so $p^{*}$ is increasing in $P$.

The probability that a project type is centralized is given by $p^{*} / P$. Since $p^{*}$ is decreasing in $A, p^{*} / P$ is also decreasing in $A$. Moreover, from the proof of Theorem 2, it is clear that if $P$ increases by, say, $\delta$, holding $A$ constant, $p^{*}$ also increases by $\delta$ and $p^{*} / P$ increases, since $p^{*} \leq P$.

Q.E.D.

THEOREM 3. If the CEO can commit to an allocation of authority ex ante but is not forced to do so, she will never commit to centralization ex ante. Given $A$ and 
$b$, there is a threshold, $\bar{P}(b, A)$, such that the CEO will not commit to delegation whenever $P>\bar{P}(b, A)$ but will commit to delegation for sufficiently small values of $P<\bar{P}(b, A)$.

Proof. Let $L_{T}$ denote the CEO's expected loss in the ex ante environment ( $T$ is for project type) and $L_{S}$ denote the CEO's expected loss in the ex post environment ( $S$ is for project specifics). Then

$$
\begin{aligned}
& L_{T}=\min \left\{L(b, A), b^{2}+L(b, P)\right\} \text { and } \\
& L_{S}=\frac{p^{*}}{P} L(b, A)+\left(1-\frac{p^{*}}{P}\right)\left[b^{2}+L\left(b, P-p^{*}\right)\right] .
\end{aligned}
$$

First assume centralization is optimal in the ex ante environment. Then

$$
L_{T}=L(b, A) \leq b^{2}+L(b, P) .
$$

In this case, $p^{*}=0$ is impossible, since that would imply that

$$
L(b, A) \geq f(b, P)
$$

as shown in the proof of Theorem 2. It is easy to show, however, that $f(b P)>$ $L(b, P)+b^{2}$. This implies that (31) contradicts (30).

If $p^{*}=P$, then $L_{S}=L(b, A)=L_{T}$, and we are done.

If $0<p^{*}<P$, then $f\left(b, P-p^{*}\right)=L(b, A)$, which, as just noted, implies $b^{2}+L\left(b, P-p^{*}\right)<L(b, A)$. But this implies $L_{S}<L(b, A)=L_{T}$.

Now suppose delegation is optimal in the ex ante environment, so that

$$
L_{T}=b^{2}+L(b, P)<L(b, A)
$$

In this case, $p^{*}=P$ is impossible, since, as shown in the proof of Theorem 2, this would imply $b^{2} \geq L(b, A)$, contradicting (32). If $p^{*}=0$, then $L_{S}=L_{T}$, and we are done. Consequently, assume $p^{*} \in(0, P)$ and let $\delta=P-p^{*}$. By the proof of Theorem 2, this requires $f(b, \delta)=L(b, A), P>\delta$, and $\delta$ is independent of $P$.

We may now write $L_{S}(P)=L(b, A)-\frac{\delta}{P} K, \forall P>\delta$, where $K=L(b, A)-$ $b^{2}-L(b, \delta)>0$, using (32), the fact that $\delta<P$, and $L$ is increasing in its second argument. Since $L(b, A)$ and $K$ are independent of $P$, it is clear that $L_{S}$ is increasing and concave in $P$. Moreover, $L_{S}(P)<L(b, A), \forall P>\delta$. Also $L_{S}(\delta)=$ $L_{T}(\delta)$ and $L_{S}^{+}(\delta)=K / \delta$, where $L_{S}^{+}$is the right derivative of $L_{S}$ with respect to $P$.

Let $L_{T}^{+}$be the right derivative of $L_{T}$. It is easy to check that

$$
L_{T}^{+}(P)+ \begin{cases}\frac{P}{6 N(b, P)^{2}}, & \text { if } P \neq x_{n}, \forall n, \\ \frac{P}{6[N(b, P)+1]^{2}}, & \text { if } P=x_{n}, \text { for some } n .\end{cases}
$$


Therefore $L_{T}^{+}(\delta) \leq \frac{\delta}{6 N(b, P)^{2}}$. It is easy to check, using $L(b, A)=f(b, \delta)$, that $K>\frac{\delta^{2}}{6 N(b, P)^{2}}$. Therefore $L_{T}^{+}(\delta)<L_{S}^{+}(\delta)$. Since $L_{T}(\delta)=L_{S}(\delta)$, it follows that $L_{T}(P)<L_{S}(P)$ for $P>\delta$ but sufficiently small. This shows that, if delegation is optimal in the ex ante environment, the CEO prefers the ex ante environment for some values of $P$.

Next, observe that

$$
\lim _{n \rightarrow \infty} L\left(b, x_{n}\right)=\lim _{n \rightarrow \infty} \frac{b x_{n}}{3}=\infty
$$

Consequently, $L_{T}(P) \equiv L(b, A)$ for $P$ sufficiently large, and therefore $L_{T}(P)$ crosses $L_{S}(P)$ at least once from below. Since $L_{S}(P)<L(b, A), \forall P>\delta$, there is a largest value of $P<\infty$ such that $L_{T}(P) \leq L_{S}(P)$. Let $\bar{P}(b, A)$ be this value of $P$.

Q.E.D.

\section{References}

Aghion, P. and Tirole, J. (1997) Formal and real authority in organizations, Journal of Political Economy 105(1), 1-29.

Aumann, R. J. and Hart, S. (2003) Long cheap talk, Econometrica 71(6), 1619-1660.

Baker, G., Gibbons, R., and Murphy, K. J. (1999) Informal authority in organizations, Journal of Law Economics and Organization 15(1), 56-73.

Berkovitch, E. and Israel, R. (2004) Why the NPV criterion does not maximize NPV, Review of Financial Studies 17, 239-255.

Bernardo, A. E., Cai, H., and Luo, J. (2001) Capital budgeting and compensation with asymmetric information and moral hazard, Journal of Financial Economics 61, 311-344.

Bhattacharyya, S. and Singh, R. (1999) The resolution of bankruptcy by auction: Allocating the residual right of design, Journal of Financial Economics 54, 269-294.

Crawford, V. P. and Sobel, J. (1982) Strategic information transmission, Econometrica 50(6), 14311451.

Dessein, W. (2002) Authority and communication in organizations, Review of Economic Studies 69, $811-838$.

Grossman, S. and Hart, O. (1986) The costs and benefits of ownership: A theory of vertical and lateral ownership, Journal of Political Economy 94, 691-719.

Harris, M. and Raviv, A. (1998) Capital budgeting and delegation, Journal of Financial Economics 50, 259-289.

Hart, O. and Moore, J. (1990) Property rights and the nature of the firm, Journal of Political Economy 98, 1119-1158.

Jensen, M. C. and Meckling, W. H. (1992) Specific and general knowledge and organizational structure, in M. C. Jensen (ed.), Foundations of Organizational Strategy, Harvard University Press, Cambridge, MA, 1998.

Krishna, V. and Morgan, J. (2004) The art of conversation: Eliciting information from experts through multi-stage communications, Journal of Economic Theory 117, 147-179.

Marino, A. M. and Matsusaka, J. G. (2005) Decision processes, agency problems, and information: An economic analysis of capital budgeting procedures, Review of Financial Studies 18(1), 301325.

Maskin, E. and Tirole, J. (1999) Two remarks on the property-rights literature, Review of Economic Studies 66, 139-149. 
Prendergast, C. (2002) The tenuous trade-off between risk and incentives, Journal of Political Economy 110, 1071-1101.

Ross, M. (1986) Capital budgeting practices of twelve large manufacturers, Financial Management $15,15-22$.

Taggart, R. A. Jr. (1987) Allocating capital among a firm's divisions: Hurdle rates vs. budgets, Journal of Financial Research 10, 177-190. 